\title{
Plasma copeptin levels are inversely associated with intima-media-thickness in men: the population-based KORA F4 study
}

\author{
Cornelia Then ${ }^{1,2^{*}}$, Bernd Kowall ${ }^{3}$, Andreas Lechner ${ }^{1,2}$, Christa Meisinger $^{4}$, Margit Heier ${ }^{4}$, Wolfgang Koenig ${ }^{6}$,
} Annette Peters ${ }^{4,5}$, Joachim Thiery ${ }^{7}$, Wolfgang Rathmann ${ }^{3 \dagger}$ and Jochen Seissler ${ }^{1,2+}$

\begin{abstract}
Background: Elevated plasma preprovasopressin (copeptin) levels are associated with cardiovascular complications as well as with an increased risk for type 2 diabetes (T2D). Here, we studied, whether plasma copeptin is related to carotid intima-media thickness (IMT), a measure of early atherosclerosis, and may thus be one explanation for the high cardiovascular risk in T2D.

Methods: Plasma concentrations of copeptin and IMT of the common carotid artery were determined in 1275 participants of the population-based KORA F4 study. We used linear regression models to investigate associations between copeptin levels and IMT.

Results: In the whole study group, copeptin levels were not significantly associated with IMT after adjustment for age and sex. Copeptin and IMT were significantly inversely associated after multivariable adjustment in the total cohort ( $\beta=-0.020 \mathrm{~mm}, 95 \% \mathrm{Cl}:-0.037 \mathrm{~mm} ;-0.003 \mathrm{~mm})$, in men $(\beta=-0.035 \mathrm{~mm}, 95 \% \mathrm{Cl}:-0.061 \mathrm{~mm} ;-0.009 \mathrm{~mm})$ and in study participants with prediabetes ( $\beta=-0.041 \mathrm{~mm}, 95 \% \mathrm{Cl}:-0.078 \mathrm{~mm} ;-0.005 \mathrm{~mm}$ ) comparing quartile 4 vs quartile 1. The negative association of copeptin and IMT in men was present after adjustment for age alone. In women and patients with T2D, copeptin was not significantly associated with IMT.

Conclusions: Plasma copeptin was not associated with an increased IMT in our study cohort. In contrast, copeptin levels were related to a lower IMT in men and subjects with prediabetes, suggesting that elevated copeptin concentrations do not exert proatherogenic effects on carotid arteries.
\end{abstract}

Keywords: Intima-media thickness, IMT, Atherosclerosis, Copeptin, AVP, Vasopressin, Diabetes

\section{Background}

The neurohormone arginine vasopressin (AVP) is secreted from the posterior pituitary in response to osmolality, hemodynamic changes and acute and chronic stress [1,2]. AVP targets various vasopressin receptors (VR), promoting antidiuretic and antinatriuretic effects via $\mathrm{V} 2 \mathrm{R}$ and mediating vasoconstriction by binding to $\mathrm{V} 1 \mathrm{aR}$ on vascular smooth muscle cells [2]. Besides these well-known

\footnotetext{
* Correspondence: cornelia.then@med.uni-muenchen.de

${ }^{\dagger}$ Equal contributors

'Medizinische Klinik und Poliklinik IV, Diabetes Zentrum - Campus Innenstadt, Klinikum der Ludwig-Maximilians-Universität, Ziemssenstrasse 1, 80336,

Munich, Germany

${ }^{2}$ Clinical Cooperation Group Diabetes, Ludwig-Maximilians-Universität München and Helmholtz Zentrum München, Munich, Germany

Full list of author information is available at the end of the article
}

functions, AVP has multiple metabolic effects: AVP activates release of adrenocorticotropic hormone from the anterior hypophysis (V2R), mediates hepatic gluconeogenesis and glycogenolysis through V1aR and stimulates glucagon and insulin secretion from pancreatic islets (V3R). In addition, AVP exerts a complex influence on the regulation of lipid metabolisms [2].

Plasma AVP is unstable and rapidly cleared from the plasma, preventing reliable measurements. Copeptin, the stable C-terminal part of the AVP precursor molecule, is cleaved from pro-AVP during processing and is secreted in an equimolar concentration with AVP. The development of assays for copeptin determination has made it possible to use copeptin as a reliable surrogate for AVP measurements [3]. 
Elevated copeptin levels are associated with the metabolic syndrome $[4,5]$, with an increased risk for type 2 diabetes (T2D) and with overt T2D [6,7]. Furthermore, plasma copeptin levels are increased in heart failure [8] and the acute coronary syndrome $[9,10]$ in both nondiabetic subjects and in patients with T2D [11-13]. Increased copeptin concentrations are related to a higher mortality in critically ill patients and provide prognostic implications in patients with end stage renal disease [14], heart failure [15], myocardial infarction [16] and stroke $[17,18]$. In addition, copeptin has been shown to be associated with all-cause mortality (hazard ratio 1.22) and cardiovascular events (hazard ratio 1.17) in diabetic patients [19]. Thus, it may be possible that increased plasma copeptin concentrations are involved in the development of premature atherosclerosis.

Measurement of intima-media thickness (IMT) of the common carotid artery by high resolution transcutaneous ultrasound is an established non-invasive measure for the early diagnosis of atherosclerosis and carotid plaque has been consistently correlated with atherosclerotic vascular lesions and with an increased risk for stroke and myocardial infarction independently of traditional vascular risk factors [20-23]. Therefore, we sought to evaluate the association of copeptin with IMT in a community-based population. The association of plasma copeptin with both cardiovascular disease $[9,10]$ and T2D [6,7] prompted us to stratify the study cohort according to categories of glucose tolerance in order to examine a possible contribution of elevated copeptin to the high cardiovascular risk in diabetes. Because previous studies have shown significant differences in plasma copeptin values in women and men $[4,5,7,24]$, we also included gender-specific analyses.

\section{Methods}

\section{Study population}

The KORA (Cooperative Health Research in the Region of Augsburg, southern Germany) F4 study is a populationbased cohort of 3080 subjects (1486 men, 1594 women) aged 32-81 years surveyed between 2006 and 2008 (follow-up study of the KORA S4 survey conducted in 1999-2001). Standardized sampling methods and data collection (medical history, medication, anthropometric measurements, blood pressure) have been described in detail elsewhere $[25,26]$. All study participants gave written informed consent and the study was approved by the Ethics Committee of the Bavarian Medical Association. IMT was measured in all study participants who agreed to undergo ultrasound examination $(n=2663)$. By study design, samples from $50 \%$ of the study participants were randomly selected for plasma copeptin measurement $(n=1596)$. All variables required for the current analyses were available in 1275 study participants. Patients were assigned to one of three groups (normal glucose tolerance
(NGT), prediabetes or T2D) according to categories of glucose tolerance. Criteria for known diabetes were a validated physician's diagnosis or current use of glucose-lowering agents. After an overnight fasting period, all non-diabetic participants underwent a standard $75 \mathrm{~g}$ oral glucose tolerance test. Newly diagnosed diabetes, impaired glucose tolerance, impaired fasting glucose and NGT were defined according to the 1999 World Health Organization diagnostic criteria based on both fasting and post-challenge glucose values ( $\geq 7.0 \mathrm{mmol} / \mathrm{l}$ fasting or $\geq 11.1 \mathrm{mmol} / \mathrm{l} 2 \mathrm{~h}$ glucose) [27]. Prediabetes was defined as increased fasting plasma glucose ( $>6.1$ and $<7.0 \mathrm{mmol} / \mathrm{l})$ and/or impaired glucose tolerance ( $2 \mathrm{~h}$ glucose $7.8-<11.1 \mathrm{mmol} / \mathrm{l})$. Hypertension was defined as systolic blood pressure $\geq 140 \mathrm{mmHg}$, diastolic blood pressure $\geq 90 \mathrm{mmHg}$ or known hypertension with use of anti-hypertensive drugs.

\section{Ultrasound and measurement of IMT}

Ultrasound measurements of common carotid arteries (CCA) were performed by two certified investigators as described recently [28]. Briefly, optimal images of the right and left CCA far wall were recorded on DVD videotapes. IMT measurements were performed off-line over a length of $10 \mathrm{~mm}$ beginning at $0-5 \mathrm{~mm}$ of the dilatation of the distal CCA using an automated edge detection reading system (Prowin software, Medical Technologies International, USA). We used the average of the measurements of the left and right CCA to calculate mean artery thickness of the distal CCA. One certified reader measured all IMT scans.

\section{Laboratory measurements}

Blood was collected without stasis and was kept at $4^{\circ} \mathrm{C}$ until centrifugation. All blood parameters, except for 2-h glucose, were based on fasting blood samples. Plasma samples were stored at $-80^{\circ} \mathrm{C}$ until assayed and there was only one freeze-thaw cycle before determination of MR-proANP. Measurements of blood glucose, HbA1c, total cholesterol, high-density lipoprotein (HDL) and low-density lipoprotein (LDL) cholesterol, triglycerides, serum creatinine and high sensitive C-reactive protein (hsCRP) were performed as described previously [29]. Glomerular filtration rate was calculated using the MDRD equation (eGFR).

Plasma concentrations of copeptin were measured by a validated sandwich fluoroimmunoassay (BRAHMS, Hennigsdorf/Berlin, Germany) using the automated system B.R.A.H.M.S KRYPTOR as described in detail elsewhere [3]. The lower detection limits was $0.4 \mathrm{pmol} / \mathrm{l}$. Intra- and inter-assay coefficients of variation were $5.9 \%$ and $8.9 \%$, respectively.

\section{Statistical analyses}

Baseline characteristics were compared between subjects with NGT, prediabetes, and T2D using F-tests in case of 
normally distributed variables. For log-normal variables, F-tests were performed on a log-scale. Logistic regression models were used to compare binomial proportions. All comparisons were adjusted for age and sex. Spearman correlation coefficients were calculated between IMT and copeptin, respectively, and conventional cardiovascular risk factors.

In linear regression models, the association between quartiles of copeptin and IMT was assessed in different models: (1) without adjustment, (2) with adjustment for age and sex, (3) for age, sex, and body mass index (BMI), and (4) age, sex, BMI, waist circumference (continuous), hypertension ( $\geq 140 / 90 \mathrm{~mm} \mathrm{Hg}$ or antihypertensive medication), HDL cholesterol (continuous), LDL cholesterol (continuous), triglycerides (continuous), prediabetes (yes/no), T2D (yes/no) former myocardial infarction or stroke, smoking behaviour (active/former/ never), alcohol consumption (never/moderate/high), physical activity (high/low), hsCRP and eGFR. These models were fitted for the whole study group, for women and men separately, and for subjects with and without impaired glucose metabolism. Furthermore, the association between copeptin and IMT was determined using copeptin as continuous variable.

As the assumptions of normally distributed residuals and of homoscedasticity were not fulfilled when IMT was the dependent variable in linear regression models, we additionally used $\ln$ (IMT) as dependent variable in linear regression models. The level of statistical significance was set at $5 \%$. All analyses were performed using the SAS version 9.2 (SAS institute, Cary, NC, USA).

\section{Results}

\section{Characteristics of the study population}

Characteristics of 1275 study participants are given in Table 1. Stratified analysis in men and women revealed higher median crude copeptin levels in men (women: 7.5 $\left(25^{\text {th }}\right.$ percentile $7.4 ; 75^{\text {th }}$ percentile 13.7$) \mathrm{pmol} / \mathrm{l}$; men: $10.1\left(25^{\text {th }}\right.$ percentile $7.4 ; 75^{\text {th }}$ percentile 13.7$) \mathrm{pmol} / \mathrm{l}$; $\mathrm{p}<0.0001)$. The copeptin levels in the respective quartiles are shown in Additional file 1: Table S1. There were also sex-specific differences in crude IMT (increased IMT by $0.043 \pm 0.008 \mathrm{~mm}$ in men, $\mathrm{p}<0.0001$ ). Both, copeptin and IMT were related with conventional cardiovascular risk factors. Age, BMI, waist circumference, systolic and diastolic blood pressure, triglycerides, HDL cholesterol, hsCRP and eGFR were all related to plasma copeptin levels in the total study cohort (Table 2). Age ( $r=0.22$ in men and 0.16 in women) and declining kidney function (eGFR; $r=-0.20$ in men and -0.16 in women) were significantly associated with copeptin levels in both genders, whereas BMI $(r=0.14)$, waist circumference $(r=0.13)$, systolic blood pressure $(r=0.08)$, triglycerides $(r=0.08)$ and hsCRP $(r=0.18)$ were significantly related to copeptin only in women (Table 2). In the total study cohort, IMT values were significantly correlated to age, BMI, LDL cholesterol, HDL cholesterol, triglycerides, systolic blood pressure, waist circumference, disturbed glucose tolerance, eGFR, and hsCRP ( $\mathrm{p}<0.0001$ for all, data not shown). Diastolic blood pressure was only slightly associated with IMT $(r=0.05, \mathrm{p}=0.05)$.

\section{Association of copeptin levels with IMT}

Analyses of the correlations between IMT and copeptin were performed separately in men and women. Unadjusted copeptin levels were not associated with IMT in men $(r=0.04 ; p=0.312)$ and only weakly associated with IMT in women $(r=0.14 ; \mathrm{p}<0.001)$. Adjustment for age, for age and BMI, and multiple linear regression analyses using copeptin as independent variable resulted in a significant inverse relation between plasma copeptin levels and IMT in men $(\beta=-0.035 \mathrm{~mm}, 95 \%$ CI: - $0.061 \mathrm{~mm}$; $-0.009 \mathrm{~mm}$; Q4 vs Q1 after multivariable adjustment). In the fully adjusted model, IMT was $0.038 \mathrm{~mm}$ (95\% CI: $-0.057 ;-0.020)$ lower in copeptin quartiles 3-4 than in quartiles $1-2$. In the total cohort, copeptin and IMT were inversely associated after multivariable adjustment $(\beta=-0.020 \mathrm{~mm}$, $95 \% \mathrm{CI}:-0.037 \mathrm{~mm} ;-0.003 \mathrm{~mm}$; Q4 vs Q1). IMT values of subjects with copeptin in quartiles $3-4$ were $0.022 \mathrm{~mm}$ (95\% CI: $-0.034 ;-0.010)$ lower than in subjects in quartiles 1-2. Using copeptin as continuous variable resulted in a significant negative relation between copeptin levels and IMT in men after multivariable adjustment (Table 3). In contrast, in women, no significant association of copeptin and IMT was detectable in any of the applied regression models. Exclusion of study participants with former myocardial infarction or stroke or an eGFR $<60 \mathrm{ml} / \mathrm{min}$ from the analyses resulted in similar findings as in the entire study cohort (Additional file 2: Table S2).

\section{Relation of copeptin with IMT depending on glucose homeostasis}

Median levels of copeptin were higher in subjects with T2D $(10.8(7.8 ; 15.2) \mathrm{pmol} / \mathrm{l})$ compared to prediabetes $(9.1(6.4 ; 12.6) \mathrm{pmol} / \mathrm{l})$ and NGT $(8.6(5.9 ; 11.4) \mathrm{pmol} / \mathrm{l})$ (Table 1). Mean IMT was $0.082 \pm 0.016 \mathrm{~mm}$ and $0.097 \pm$ $0.016 \mathrm{~mm}$ higher in women and men with T2D as compared to individuals with NGT $(\mathrm{p}<0.0001)$. This association disappeared after multivariable adjustment for conventional cardiovascular risk factors. A significant inverse correlation of IMT and copeptin was apparent in normoglycemic subjects and in study participants with prediabetes after adjustment for age, sex and BMI and after multivariable adjustment (Table 4). Using copeptin as continuous variable resulted in a significant negative 
Table 1 Characteristics of 1275 study participants according to categories of glucose regulation: the KORA F4 study ${ }^{a}$

\begin{tabular}{|c|c|c|c|c|c|}
\hline & All subjects & NGT & Prediabetes & T2D & $p^{b}$ \\
\hline $\mathbf{n}$ & 1275 & 911 & 224 & 140 & - \\
\hline Age (years) & $56.6 \pm 12.7$ & $53.4 \pm 12.2$ & $63.6 \pm 10.5$ & $66.1 \pm 8.6$ & $0.001^{\#}$ \\
\hline Sex (male) (n (\%)) & $624(48.9)$ & $419(46.0)$ & $120(53.6)$ & $85(60.7)$ & $0.003^{\# \# \#}$ \\
\hline $\mathrm{BMI}\left(\mathrm{kg} / \mathrm{m}^{2}\right)$ & $27.4 \pm 4.5$ & $26.5 \pm 4.2$ & $29.4 \pm 4.3$ & $30.6 \pm 4.4$ & $0.001^{\#}$ \\
\hline Waist (cm) & $93.3 \pm 13.6$ & $90.2 \pm 12.9$ & $99.4 \pm 11.9$ & $103.9 \pm 11.7$ & $0.001^{\#}$ \\
\hline Systolic blood pressure (mm Hg) & $122.1 \pm 17.7$ & $119.0 \pm 16.7$ & $128.9 \pm 18.1$ & $131.3 \pm 16.7$ & $0.001^{\#}$ \\
\hline Diastolic blood pressure $(\mathrm{mm} \mathrm{Hg})$ & $75.1 \pm 9.6$ & $74.8 \pm 9.4$ & $76.8 \pm 9.9$ & $74.7 \pm 10.2$ & $0.003^{\#}$ \\
\hline HDL cholesterol (mmol/l) & $1.47 \pm 0.37$ & $1.51 \pm 0.38$ & $1.41 \pm 0.35$ & $1.29 \pm 0.29$ & $0.001^{\#}$ \\
\hline LDL cholesterol (mmol/l) & $3.52 \pm 0.88$ & $3.49 \pm 0.86$ & $3.80 \pm 0.92$ & $3.28 \pm 0.85$ & $0.001^{\#}$ \\
\hline Triglycerides (mmol/l) & $102.0(71.0,149.0)$ & $93.0(65.0 ; 136.0)$ & $126.0(93.0 ; 172.5)$ & $130.5(92.0 ; 206.0)$ & $0.001^{\# \#}$ \\
\hline hsCRP (mg/l) & $1.10(0.54 ; 2.42)$ & $0.935(0.46 ; 1.95)$ & $1.71(0.92 ; 3.40)$ & $1.70(0.86 ; 3.76)$ & $0.001^{\# \#}$ \\
\hline Estimated GFR (ml/min) & $84.0 \pm 18.2$ & $85.8 \pm 17.6$ & $81.3 \pm 18.2$ & $76.8 \pm 19.8$ & $0.12^{\#}$ \\
\hline Former stroke or MI (n (\%)) & $58(4.6)$ & $30(3.3)$ & $10(4.5)$ & $18(12.9)$ & $0.03^{\# \# \#}$ \\
\hline Active or former smoker (n (\%)) & $728(57.1)$ & $534(58.6)$ & $110(49.1)$ & $84(60.0)$ & $0.049^{\# \# \#}$ \\
\hline High alcohol consumption $(\mathrm{n}(\%))^{c}$ & $249(19.5)$ & $179(19.7)$ & $42(18.8)$ & $28(20.0)$ & $0.92^{\# \# \#}$ \\
\hline Hypertension $(\mathrm{n}(\%))^{\mathrm{d}}$ & $500(39.3)$ & $265(29.1)$ & $127(56.7)$ & $108(77.1)$ & $0.001^{\# \# \#}$ \\
\hline Physically inactive $(\mathrm{n}(\%))^{\mathrm{e}}$ & $529(41.5)$ & $341(37.4)$ & $110(49.1)$ & $78(55.7)$ & $0.001^{\# \# \#}$ \\
\hline \multicolumn{6}{|l|}{ Copeptin (pmol/l) } \\
\hline Mean \pm SD & $10.46 \pm 16.46$ & $9.97 \pm 16.73$ & $9.94 \pm 7.20$ & $14.5 \pm 23.4$ & $0.02^{\# \#}$ \\
\hline Median ( $25^{\text {th }}$ percentile, $75^{\text {th }}$ percentile) & $8.91(6.13 ; 12.00)$ & $8.59(5.90 ; 11.35)$ & $9.10(6.42 ; 12.64)$ & $10.84(7.80 ; 15.16)$ & \\
\hline \multicolumn{6}{|l|}{ Intima-media-thickness (mm) } \\
\hline Mean \pm SD & $0.85 \pm 0.14$ & $0.82 \pm 0.13$ & $0.91 \pm 0.14$ & $0.92 \pm 0.14$ & $0.19^{\# \#}$ \\
\hline Median ( $25^{\text {th }}$ percentile, $75^{\text {th }}$ percentile) & $0.83(0.74 ; 0.93)$ & $0.80(0.73 ; 0.89)$ & $0.90(0.80 ; 1.01)$ & $0.90(0.82 ; 1.02)$ & \\
\hline
\end{tabular}

All analyses are adjusted for age and sex.

Abbreviations: NGT normal glucose tolerance, T2D type 2 diabetes mellitus, BMI body mass index, MI myocardial infarction, $h$ sCRP high sensitive C-reactive protein (serum).

${ }^{\text {a }}$ Mean \pm standard deviation, median $\left(25^{\text {th }}\right.$ percentile, $75^{\text {th }}$ percentile), proportions (\%).

b "F-Test; "\#log F-Test; ${ }^{\# \# \# ~ l o g i s t i c ~ r e g r e s s i o n . ~}$

'High alcohol intake: $\geq 40 \mathrm{~g} /$ day in men, $\geq 20 \mathrm{~g} /$ day in women.

${ }^{d}$ Systolic blood pressure $\geq 140 / 90 \mathrm{~mm} \mathrm{Hg}$ or antihypertensive medication.

éess than 1 hour of physical activity per week.

relation between copeptin levels and IMT in study participants with prediabetes after adjustment for age and sex, for age, sex and BMI and after multivariable adjustment (Table 4). There was no significant association of copeptin and IMT in patients with overt T2D.

\section{Discussion}

\section{Inverse association of copeptin levels with IMT}

The key finding of the present study is a significant inverse relation of copeptin plasma levels with IMT in a community-based cohort. Our data suggest that moderately increased copeptin concentrations may indicate a reduced risk of early carotid atherosclerotic lesions in men. Our finding is unexpected, since AVP was considered to exert mainly proatherogenic effects and previous studies suggest a link between AVP/copeptin and the development of vascular complications [9-11,16-18]. Copeptin has negative prognostic value for all-cause mortality in severe disorders, such as heart failure [8,30-32], coronary artery disease [33,34], acute myocardial infarction [35] and stroke [17], and end-stage renal disease [14], whereas, to our knowledge, copeptin has not been described as a risk factor for future cardiovascular events in stable patients. Plasma copeptin levels do not reflect coronary artery status in stable patients with coronary artery disease $[36,37]$ or predict cardiovascular events and incident heart failure in population-based studies [37-39]. In line with these results our study demonstrates that circulating copeptin is not an indicator for early atherosclerosis.

What is a possible explanation for the observed inverse association between copeptin and IMT? AVP is not only involved in vasoconstriction but also in nitric oxide-mediated vasorelaxation through the binding to the oxytocin receptor on vascular endothelium $[2,40]$. Experimental studies showed that AVP infusion in 
Table 2 Spearman correlation coefficients ( $p$ values) between copeptin levels and cardiovascular risk factors $(n=1596)$

\begin{tabular}{|c|c|c|c|}
\hline & Total sample $(n=1596)$ & Men $(n=780)$ & Women $(n=816)$ \\
\hline Age & $0.187(<0.001)$ & $0.217(<0.001)$ & $0.157(<0.001)$ \\
\hline BMI & $0.106(<0.001)$ & $-0.020(0.57)$ & $0.139(<0.001)$ \\
\hline Waist circumference & $0.201(<0.001)$ & $0.014(0.69)$ & $0.126(<0.001)$ \\
\hline Systolic blood pressure & $0.139(<0.001)$ & $0.014(0.70)$ & $0.080(0.02)$ \\
\hline Diastolic blood pressure & $0.051(0.04)$ & $-0.056(0.12)$ & $0.002(0.94)$ \\
\hline Triglycerides & $0.094(<0.001)$ & $-0.020(0.58)$ & $0.078(0.03)$ \\
\hline HDL cholesterol & $-0.135(<0.001)$ & $0.011(0.75)$ & $-0.054(0.12)$ \\
\hline hsCRP & $0.139(<0.001)$ & $0.115(0.001)$ & $0.179(<0.001)$ \\
\hline eGFR & $-0.142(<0.001)$ & $-0.200(<0.001)$ & $-0.156(<0.001)$ \\
\hline
\end{tabular}

normotensive rats results not only in blood pressure increase, but also a V1R-mediated active vasodilatation of carotid arteries, probably mediated by endothelial release of nitric oxide [40], which plays an essential role in protection against vascular inflammation and endothelial dysfunction. The net effect of circulating AVP on the vascular bed may depend on the absolute hormone concentration [2]. In the present study, the median copeptin level was 8.6-9.1 pmol/l in non-diabetic individuals, which is comparable to levels described in other population-based studies (ranging from $5.0 \mathrm{pmol} / 1$ to 8.2 $\mathrm{pmol} / \mathrm{l}[4,6,7,41])$, but 2 -10-fold lower than reported in studies investigating severe disorders, such as stroke, myocardial infarction or end stage kidney disease $[9,14,42]$. High AVP plasma concentrations predominantly stimulate $\mathrm{V} 1 \mathrm{aR}$, mediating vasoconstriction [43] and possibly increasing the prothrombotic potential by platelet activation [44]. Whereas high AVP levels are proatherogenic or indirectly indicate an increased risk for fatal complications, intermediate AVP concentrations may exert an inert or even protective effect on vascular endothelium. This hypothesis needs to be confirmed in future experimental studies.

So far, only few studies have investigated the association between copeptin concentrations and the development and progression of chronic atherosclerosis in the general community. One study found elevated copeptin concentrations to be associated with a decreased anklebrachial index in patients with peripheral arterial disease. However, this association was only significant in African-Americans, but not in non-Hispanic whites, and all study participants had a family history of hypertension [45]. Another study described a positive association between copeptin levels and IMT in middle-aged individuals with chronic kidney disease [46] and a further study reported that copeptin is a predictor of stroke in hemodialysis patients [14]. Additionally, high copeptin levels predict microalbuminuria, an early sign of target organ damage in diabetes and hypertension [24,47]. However, high AVP plasma levels probably promote microalbuminuria primarily via V2R, a pathway not necessarily connected to atherosclerotic changes. Moreover, patients with renal insufficiency differ from the present population in several aspects. Chronic kidney disease patients are at high risk for cardiovascular events, often suffer from disturbances of sodium homeostasis and may have an overly activated AVP system. In addition, kidney function has a major impact on copeptin clearance [48]. Therefore, the discrepant results may be explained by different study population characteristics.

The effect of elevated AVP levels may depend on the receptor subtype distribution and regulation. AVP has been shown to exert certain pathophysiological effects in a gender-specific manner, e.g. a higher anti-diuretic response in females, probably due to a higher V2R density in the collecting duct and a decreased blood and pulse pressure sensitivity $[49,50]$. While, in rats, AVP induces a stronger contraction of coronary arteries in males [51], maximal contraction of the aorta in response to vasopressin is about threefold higher in females due to a weaker endothelium-derived nitric oxide-mediated vasodilatation [52]. In addition, potentially protective vasopressin effects seem to be more present in men. For example, a V2-like receptor related vasodilator effect exists in male rats, but not in females [53]. Thus, females seem to be less well protected against harmful vascular AVP. This might be one explanation for the lacking relationship between copeptin and IMT in women.

\section{Relation of copeptin with IMT depending on glucose homeostasis}

After stepwise adjustment for age and sex, for age, sex and BMI and in the multivariate model, copeptin displayed significant associations with IMT only in subjects with NGT and with disturbed glucose tolerance, but not in patients with overt T2D. As described in previous studies [5-7], we found an increase of plasma copeptin in patients with T2D. Assuming that at least part of diabetic patients have high fasting blood glucose, the observed attenuation of the relation between copeptin and 
Table 3 Association of plasma copeptin levels and IMT

$\begin{array}{cccc}\text { Copeptin } & \text { Copeptin } & \text { Copeptin } & \begin{array}{c}\beta \text { per 1 SD } \\ \text { increase in } \\ \text { copeptin }\end{array}\end{array}$

No adjustment

All subjects $(\mathrm{N}=1,275)$

Men $(N=624)$

Women $(\mathrm{N}=651)$

Adjusted for age and sex

All subjects

Men

Women

Adjusted for age, sex and BMI

All subjects

Men

Women

Multivariable adjustment

All subjects

Men

Women

Women
0.010

$(-0.005 ; 0.026)$

$$
-0.013
$$

$(-0.036 ; 0.011)$

0.032

(0.012; 0.052)

$$
-0.018
$$

(-0.030; -0.006)

$-0.042$

$(-0.060 ;-0.023)$

0.005

$(-0.011 ; 0.020)$

\section{$-0.018$}

(-0.030; -0.006)

$-0.039$

(-0.057; -0.020)

0.002

$(-0.013 ; 0.018)$

$(-0.034 ;-0.010)$

$-0.038$

(-0.057; -0.020)

$-0.002$

$(-0.017 ; 0.014)$
0.023

(0.005; 0.041)

0.016

$(-0.011 ; 0.043)$

0.030

(0.007; 0.053)

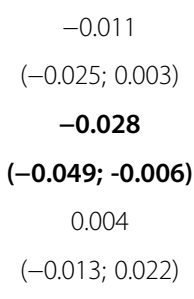

$-0.012$

(-0.026; 0.002)

$-0.026$

$(-0.048 ;-0.005)$

0.002

$(-0.016 ; 0.020)$

$-0.014$

(-0.028; -0.0002)

$-0.024$

$(-0.046 ;-0.002)$

$-0.001$

$(-0.019 ; 0.017)$
0.028

0.005

(0.006; 0.050)

0.009

$(-0.003 ; 0.013)$

0.002

$(-0.024 ; 0.042)$

0.046

$(-0.010 ; 0.014)$

0.008

(0.018; 0.074)

$(-0.002 ; 0.018)$

-0.015
$(-0.033 ; 0.002)$

$-0.038$

$-0.001$

$(-0.007 ; 0.005)$

$-0.009$

$(-0.064 ;-0.011)$

$(-0.018 ; 0.001)$

0.005

$(-0.002 ; 0.013)$

$(-0.016 ; 0.027)$

$-0.002$

(-0.008; 0.004)

$-0.009$

(-0.018; 0.0002)

0.004

(-0.003; 0.012)

$(-0.019 ; 0.024)$

$-0.003$

(-0.009; 0.003)

$-0.010$

$(-0.020 ;-0.001)$

0.004

(-0.004; 0.012)

Gender-specific adjusted $\beta_{\text {'s }}(95 \%$ Cl) for IMT given in mm as dependent variable and categories of copeptin as independent variable (highest quartile Q4 or Q3-4 versus lower quartiles (reference)): Results of linear regression models.

adjusted for: age, sex, BMl, waist (continuous), hypertension (systolic blood pressure $\geq 140 / 90 \mathrm{~mm}$ Hg or antihypertensive medication), HDL cholesterol (continuous), LDL cholesterol (continuous), triglycerides (continuous), former myocardial infarction or stroke, smoking (active/former/never), alcohol consumption (abstinent/moderate/high), physical activity (high/low), hsCRP, eGFR, prediabetes (yes/no), T2D (yes/no).

bold: $\mathrm{p}<0.05$.

IMT may be explained to some extent by a slightly increased plasma osmolality followed by activation of the AVP system. It is tempting to speculate that the osmolalitymediated AVP/copeptin release might result in hormone concentrations that are above the threshold value predominantly mediating protective vascular effects. Alternatively, additional risk factors may be present in diabetic patients, overriding the potential protective effect of copeptin. It is important to note that we observed a trend towards an inverse correlation between plasma copeptin and IMT also in patients with T2D, suggesting that elevated copeptin is not a risk factor for early carotid atherosclerosis in patients with
T2D. This interpretation is in agreement with a recent prospective study in diabetic patients showing that copeptin is related to all-cause mortality but only non-significantly associated with cardiovascular events [19].

\section{Study limitations}

The major limitation of our study is its cross-sectional design, precluding statements on causalities. Furthermore, although multivariable adjustments were performed for all traditional cardiovascular risk factors and other potentially confounding parameters, residual confounding cannot be excluded. 
Table 4 Association of copeptin levels and IMT according to categories of glucose homeostasis

$\begin{array}{cccc}\text { Copeptin } & \text { Copeptin } & \text { Copeptin } & \begin{array}{c}\beta \text { per 1 SD } \\ \text { increase in } \\ \text { copeptin }\end{array} \\ \text { Q3-4 vs Q1-2 } & \text { Q4 vs Q1-Q3 } & \text { Q4 vs Q1 } & \text { coptin }\end{array}$

Total study cohort

No adjustment

NGT $(n=911)$

Prediabetes $(n=224)$

$$
0.007
$$

$(-0.010 ; 0.025)$

$\mathrm{T} 2 \mathrm{D}(\mathrm{n}=140)$

$-0.010$

$(-0.046 ; 0.027)$

$-0.018$

$(-0.068 ; 0.032)$

Adjustment for age and sex

NGT

$-0.015$

(-0.029; -0.002)

Prediabetes

$-0.028$

$(-0.060 ; 0.004)$

T2D

$-0.025$

$(-0.071 ; 0.020)$

Adjusted for age, sex and BMI

NGT

$-0.016$

$(-0.029 ;-0.003)$

Prediabetes

$-0.027$

$(-0.058 ; 0.005)$

T2D

$-0.025$

$(-0.070 ; 0.021)$

Multivariable adjustment ${ }^{\mathrm{a}}$

NGT

$-0.018$

$(-0.031 ;-0.005)$

Prediabetes

$-0.031$

$(-0.064 ; 0.002)$

T2D
0.019

$(-0.002 ; 0.040)$

$-0.009$

(-0.049; 0.031)

$-0.003$

$(-0.051 ; 0.046)$

$-0.004$

(-0.020; 0.012)

$-0.040$

$(-0.075 ;-0.005)$

$-0.009$

$(-0.054 ; 0.035)$

$$
\begin{gathered}
-0.006 \\
(-0.022 ; 0.010)
\end{gathered}
$$

$-0.038$

(-0.073; -0.004)

$-0.008$

$(-0.053 ; 0.037)$

(-0.023; 0.008)

$-0.041$

$(-0.078 ;-0.005)$

$-0.009$

$(-0.059 ; 0.040)$

$$
\begin{gathered}
0.024 \\
(-0.001 ; 0.049) \\
-0.024 \\
(-0.075 ; 0.027) \\
0.001 \\
(-0.076 ; 0.077)
\end{gathered}
$$

$-0.007$

(-0.026; 0.012)

$-0.058$

(-0.103; -0.014)

$-0.008$

$(-0.078 ; 0.062)$

$-0.008$

(-0.027; 0.011)

$-0.057$

$(-0.101 ;-0.013)$

$-0.007$

$(-0.078 ; 0.063)$

$-0.009$

$(-0.028 ; 0.010)$

$-0.066$

$(-0.112 ;-0.019)$

$-0.018$

$(-0.096 ; 0.060)$
0.001

$(-0.008 ; 0.010)$

$-0.011$

$(-0.055 ; 0.032)$

0.009

$(-0.006 ; 0.024)$

$-0.004$

$(-0.011 ; 0.002)$

$-0.044$

$(-0.082 ;-0.006)$

0.010

$(-0.003 ; 0.024)$

$-0.005$

$(-0.012 ; 0.002)$

$-0.042$

(-0.079; -0.004)

0.010

$(-0.003 ; 0.024)$

$-0.006$

$(-0.013 ; 0.0002)$

$-0.050$

$(-0.091 ;-0.009)$

0.012

$(-0.002 ; 0.026)$

Gender-specific adjusted $\beta^{\prime}$ s $(95 \% \mathrm{Cl})$ according to categories of glucose tolerance for IMT as dependent variable and categories of copeptin as independent variable (highest quartile Q4 or Q3-4 versus lower quartiles (reference)): Results of linear regression models.

${ }^{a}$ Adjusted for: age, sex, BMI, waist (continuous), hypertension (systolic blood pressure $\geq 140 / 90 \mathrm{~mm} \mathrm{Hg}$ or antihypertensive medication), $\mathrm{HDL}$ cholesterol (continuous), LDL cholesterol (continuous), triglycerides (continuous), former myocardial infarction or stroke, smoking (active/former/never), alcohol consumption (abstinent/moderate/high), physical activity (high/low), hsCRP, eGFR.

bold: $\mathrm{p}<0.05$.

\section{Conclusions}

We provide the first data on the association of copeptin with IMT in a large population-based cohort stratified by gender, impaired glucose tolerance and T2D. We found an inverse association of copeptin and IMT, suggesting that moderately increased copeptin concentrations are related to a lower degree of atherosclerotic alterations in the CCA. Thus, plasma copeptin does not seem to be an independent risk factor for early carotid atherosclerosis in the general population. Whether slightly increased copeptin concentrations may be protective from macrovascular complications needs to be investigated in a prospective epidemiological study.

\section{Additional files}

Additional file 1: Table S1. Copeptin values in the respective quartiles. Additional file 2: Table S2. Relation of plasma copeptin and IMT. Gender-specific adjusted $\beta^{\prime}$ s (95\% Cl) for IMT given in mm as dependent variable and categories of copeptin as independent variable (highest quartile Q4 versus lowest quartile Q1): Results of linear regression models excluding study participants with former myocardial infarction or stroke or with an $\mathrm{eGFR}<60 \mathrm{ml} / \mathrm{min}$. 


\section{Abbreviations}

AVP: Arginine vasopressin; BMI: Body mass index; CCA: Common carotid artery; Cl: Confidence interval; eGFR: Estimated glomerular filtration rate; HDL: Highdensity lipoprotein; hsCRP: High sensitive C-reactive protein; IMT: Intima-media thickness; KORA: Cooperative Health Research in the Region of Augsburg; LDL: Low-density lipoprotein; Ml: Myocardial infarction; NGT: Normal glucose tolerance; OR: Odds ratio; Q: Quartile; r: Sperman correlation coefficient; T2D: Type 2 diabetes; VR: Vasopressin receptor; vs: Versus.

\section{Competing interests}

The authors report that there is no duality of interest associated with this manuscript.

\section{Authors' contribution}

$C T, B K, A L, C M, A P, W R$ and JS participated in the conception and design of the study; CT, CM, MH, WK, AP, JT, WR, JS collected the data; CT, BK, WR and JS analyzed the data; CT, BK, AL, CM, MH, WK, AP, JT, WR and JS participated in the interpretation of the results and the writing of the manuscript. All authors read and approved the final manuscript.

\section{Acknowledgments}

The KORA research platform studies were initiated and financed by the Helmholtz Zentrum München-German Research Center for Environmental Health, which is funded by the German Federal Ministry of Education, Science, Research and Technology and by the State of Bavaria. The KORA study group consists of A. Peters (speaker), J. Heinrich, R. Holle, R. Leidl, C. Meisinger, K. Strauch, and their coworkers, who are responsible for the design and conduct of the KORA studies. We gratefully acknowledge the contribution of all members of field staffs conducting the KORA F4 study and thank all study participants. Furthermore, we thank Monika Offers and Katharina Antrack for excellent technical assistance. The study was supported by a research grant from the Virtual Diabetes Institute (Helmholtz Zentrum München) and the Clinical Cooperation Group Diabetes, Ludwig-MaximiliansUniversity München and Helmholtz Zentrum München. Further support was obtained from the Federal Ministry of Health and the Ministry of Innovation, Science, Research and Technology of the state North Rhine Westphalia. Measurement of vasoactive polypetides and IMT was partly funded by grants of the Karl-Wilder-Foundation (J.S.) and the Deutsche Diabetes-Gesellschaft (C.T.). The KORA F4 study was partly funded by a grant of the German Research Foundation (DFG) (RA-45913/3-1).

\section{Author details}

'Medizinische Klinik und Poliklinik IV, Diabetes Zentrum - Campus Innenstadt, Klinikum der Ludwig-Maximilians-Universität, Ziemssenstrasse 1, 80336, Munich, Germany. ${ }^{2}$ Clinical Cooperation Group Diabetes, Ludwig-Maximilians-Universität München and Helmholtz Zentrum München, Munich, Germany. ${ }^{3}$ German Diabetes Center, Leibniz Institute at Heinrich Heine University Düsseldorf, Institute of Biometrics and Epidemiology, Düsseldorf, Germany. ${ }^{4}$ Institute of Epidemiology II, Helmholtz Zentrum München - German Research Center for Environmental Health (GmbH), Neuherberg, Germany. ${ }^{5}$ Research Unit of Molecular Epidemiology, German Research Center for Environmental Health, Neuherberg, Germany. ${ }^{6}$ Department of Internal Medicine II - Cardiology, University of UIm, Medical Centre, Ulm, Germany. ${ }^{7}$ Institute of Laboratory Medicine, Clinical Chemistry and Molecular Diagnostics, University Hospital Leipzig, Leipzig, Germany.

Received: 28 August 2013 Accepted: 3 November 2013

Published: 11 November 2013

\section{References}

1. Morgenthaler NG: Copeptin: a biomarker of cardiovascular and renal function. Congest Heart Fail 2010, 16(Suppl 1):S37-S44.

2. Holmes $C L$, Landry DW, Granton JT: Science review: vasopressin and the cardiovascular system part 2 - clinical physiology. Crit Care 2004, 8:15-23.

3. Morgenthaler NG, Struck J, Alonso C, Bergmann A: Assay for the measurement of copeptin, a stable peptide derived from the precursor of vasopressin. Clin Chem 2006, 52:112-119.

4. Saleem U, Khaleghi M, Morgenthaler NG, Bergmann A, Struck J, Mosley TH Jr, Kullo IJ: Plasma carboxy-terminal provasopressin (copeptin): a novel marker of insulin resistance and metabolic syndrome. J Clin Endocrinol Metab 2009, 94:2558-2564.
5. Enhorning S, Struck J, Wirfalt E, Hedblad B, Morgenthaler NG, Melander O: Plasma copeptin, a unifying factor behind the metabolic syndrome. J Clin Endocrinol Metab 2011, 96:E1065-E1072.

6. Enhorning S, Wang TJ, Nilsson PM, Almgren P, Hedblad B, Berglund G, Struck J, Morgenthaler NG, Bergmann A, Lindholm E, Groop L, Lyssenko V, Orho-Melander M, Newton-Cheh C, Melander O: Plasma copeptin and the risk of diabetes mellitus. Circulation 2010, 121:2102-2108.

7. Abbasi A, Corpeleijn E, Meijer E, Postmus D, Gansevoort RT, Gans RO, Struck J, Hillege HL, Stolk RP, Navis G, Bakker SJ: Sex differences in the association between plasma copeptin and incident type 2 diabetes: the Prevention of Renal and Vascular Endstage Disease (PREVEND) study. Diabetologia 2012, 55:1963-1970

8. Gegenhuber A, Struck J, Dieplinger B, Poelz W, Pacher R, Morgenthaler NG, Bergmann A, Haltmayer M, Mueller T: Comparative evaluation of B-type natriuretic peptide, mid-regional pro-A-type natriuretic peptide, mid-regional pro-adrenomedullin, and Copeptin to predict 1-year mortality in patients with acute destabilized heart failure. J Card Fail 2007, 13:42-49.

9. Reichlin T, Hochholzer W, Stelzig C, Laule K, Freidank H, Morgenthaler NG, Bergmann A, Potocki M, Noveanu M, Breidthardt T, Christ A, Boldanova T, Merki R, Schaub N, Bingisser R, Christ M, Mueller C: Incremental value of copeptin for rapid rule out of acute myocardial infarction. J Am Coll Cardiol 2009, 54:60-68

10. Keller T, Tzikas S, Zeller T, Czyz E, Lillpopp L, Ojeda FM, Roth A, Bickel C, Baldus S, Sinning CR, Wild PS, Lubos E, Peetz D, Kunde J, Hartmann O, Bergmann A, Post F, Lackner K, Genth-Zotz S, Nicaud V, Tiret L, Munzel TF, Blankenberg S: Copeptin improves early diagnosis of acute myocardial infarction. J Am Coll Cardiol 2010, 55:2096-2106.

11. Mellbin LG, Ryden L, Brismar K, Morgenthaler NG, Ohrvik J, Catrina SB: Copeptin, IGFBP-1, and cardiovascular prognosis in patients with type 2 diabetes and acute myocardial infarction: a report from the DIGAMI 2 trial. Diabetes Care 2010, 33:1604-1606.

12. Maier C, Clodi M, Neuhold S, Resl M, Elhenicky M, Prager R, Moertl D, Strunk G, Luger A, Struck J, Pacher R, Hulsmann M: Endothelial markers may link kidney function to cardiovascular events in type 2 diabetes. Diabetes Care 2009, 32:1890-1895.

13. Boertien WE, Riphagen IJ, Drion I, Alkhalaf A, Bakker SJ, Groenier KH, Struck J, de Jong PE, Bilo HJ, Kleefstra N, Gansevoort RT: Copeptin, a surrogate marker for arginine vasopressin, is associated with declining glomerular filtration in patients with diabetes mellitus (ZODIAC-33). Diabetologia 2013, 56:1680-1688.

14. Fenske W, Wanner C, Allolio B, Drechsler C, Blouin K, Lilienthal J, Krane V: Copeptin levels associate with cardiovascular events in patients with ESRD and type 2 diabetes mellitus. J Am Soc Nephrol 2011, 22:782-790.

15. Voors AA, von Haehling S, Anker SD, Hillege HL, Struck J, Hartmann O, Bergmann A, Squire I, van Veldhuisen DJ, Dickstein K: C-terminal provasopressin (copeptin) is a strong prognostic marker in patients with heart failure after an acute myocardial infarction: results from the OPTIMAAL study. Eur Heart J 2009, 30:1187-1194.

16. von Haehling S, Papassotiriou J, Morgenthaler NG, Hartmann O, Doehner W, Stellos K, Wurster T, Schuster A, Nagel E, Gawaz M, Bigalke B: Copeptin as a prognostic factor for major adverse cardiovascular events in patients with coronary artery disease. Int I Cardiol 2012, 162:27-32

17. Katan M, Fluri F, Morgenthaler NG, Schuetz P, Zweifel C, Bingisser R, Muller K, Meckel S, Gass A, Kappos L, Steck AJ, Engelter ST, Muller B, Christ-Crain M: Copeptin: a novel, independent prognostic marker in patients with ischemic stroke. Ann Neurol 2009, 66:799-808.

18. De Marchis GM, Katan M, Weck A, Fluri F, Foerch C, Findling O, Schuetz P, Buhl D, El-Koussy M, Gensicke H, Seiler M, Morgenthaler N, Mattle HP, Mueller B, Christ-Crain M, Arnold M: Copeptin adds prognostic information after ischemic stroke: results from the CoRisk study. Neurology 2013, 80:1278-1286.

19. Riphagen IJ, Boertien WE, Alkhalaf A, Kleefstra N, Gansevoort RT, Groenier KH, van Hateren KJ, Struck J, Navis G, Bilo HJ, Bakker SJ: Copeptin, a surrogate marker for arginine vasopressin, is associated with cardiovascular and All-cause mortality in patients with type 2 diabetes (ZODIAC-31). Diabetes Care 2013, 36:3201-3207.

20. Kavousi M, Elias-Smale S, Rutten JH, Leening MJ, Vliegenthart R, Verwoert GC, Krestin GP, Oudkerk M, de Maat MP, Leebeek FW, Mattace-Raso FU, Lindemans J, Hofman A, Steyerberg EW, van der Lugt A, van den Meiracker $\mathrm{AH}$, Witteman JC: Evaluation of newer risk markers for coronary heart disease risk classification: a cohort study. Ann Intern Med 2012, 156:438-444. 
21. Nambi V, Chambless L, Folsom AR, He M, Hu Y, Mosley T, Volcik K, Boerwinkle E, Ballantyne CM: Carotid intima-media thickness and presence or absence of plaque improves prediction of coronary heart disease risk: the ARIC (Atherosclerosis Risk In Communities) study. J Am Coll Cardiol 2010, 55:1600-1607.

22. Polak JF, Pencina MJ, Pencina KM, O'Donnell CJ, Wolf PA, D'Agostino RB Sr: Carotid-wall intima-media thickness and cardiovascular events. N Engl J Med 2011, 365:213-221.

23. Thakore AH, Guo CY, Larson MG, Corey D, Wang TJ, Vasan RS, D'Agostino RB Sr, Lipinska I, Keaney JF Jr, Benjamin EJ, O'Donnell CJ: Association of multiple inflammatory markers with carotid intimal medial thickness and stenosis (from the Framingham Heart Study). Am J Cardiol 2007 99:1598-1602.

24. Meijer E, Bakker SJ, Halbesma N, de Jong PE, Struck J, Gansevoort RT: Copeptin, a surrogate marker of vasopressin, is associated with microalbuminuria in a large population cohort. Kidney Int 2010, 77:29-36

25. Meisinger C, Ruckert IM, Rathmann W, Doring A, Thorand B, Huth C, Kowal B, Koenig W: Retinol-binding protein 4 is associated with prediabetes in adults from the general population: the Cooperative Health Research in the Region of Augsburg (KORA) F4 Study. Diabetes Care 2011, 34:1648-1650

26. Rathmann W, Strassburger K, Heier M, Holle R, Thorand B, Giani G, Meisinger C: Incidence of Type 2 diabetes in the elderly German population and the effect of clinical and lifestyle risk factors: KORA S4/F4 cohort study. Diabet Med 2009, 26:1212-1219.

27. Rathmann W, Haastert B, Icks A, Lowel H, Meisinger C, Holle R, Giani G: High prevalence of undiagnosed diabetes mellitus in Southern Germany: target populations for efficient screening. The KORA survey 2000 Diabetologia 2003, 46:182-189.

28. Kowall B, Ebert N, Then C, Thiery J, Koenig W, Meisinger C, Rathmann W, Seissler J: Associations between blood glucose and carotid intima-media thickness disappear after adjustment for shared risk factors: the KORA F4 study. PLoS One 2012, 7:e52590

29. Seissler J, Feghelm N, Then C, Meisinger C, Herder C, Koenig W, Peters A Roden M, Lechner A, Kowall B, Rathmann W: Vasoregulatory peptides pro-endothelin-1 and pro-adrenomedullin are associated with metabolic syndrome in the population-based KORA F4 study. Eur J Endocrinol 2012, $167: 847-853$.

30. Neuhold S, Huelsmann M, Strunk G, Stoiser B, Struck J, Morgenthaler NG, Bergmann A, Moertl D, Berger R, Pacher R: Comparison of copeptin, B-type natriuretic peptide, and amino-terminal pro-B-type natriuretic peptide in patients with chronic heart failure: prediction of death at different stages of the disease. J Am Coll Cardiol 2008, 52:266-272.

31. Kelly D, Squire IB, Khan SQ, Quinn P, Struck J, Morgenthaler NG, Davies JE, $\mathrm{Ng}$ LL: C-terminal provasopressin (copeptin) is associated with left ventricular dysfunction, remodeling, and clinical heart failure in survivors of myocardial infarction. J Card Fail 2008, 14:739-745.

32. Stoiser B, Mortl D, Hulsmann M, Berger R, Struck J, Morgenthaler NG, Bergmann A, Pacher R: Copeptin, a fragment of the vasopressin precursor, as a novel predictor of outcome in heart failure. Eur J Clin Invest 2006, 36:771-778.

33. Staub D, Morgenthaler NG, Buser C, Breidthardt T, Potocki M, Noveanu M, Reichlin T, Bergmann A, Mueller C: Use of copeptin in the detection of myocardial ischemia. Clin Chim Acta 2009, 399:69-73.

34. Chai SB, Hui YM, Li XM, Xiao Y, Tang CS: Plasma levels of copeptin in patients with coronary heart disease. Heart Vessels 2009, 24:79-83.

35. Khan SQ, Dhillon OS, O'Brien RJ, Struck J, Quinn PA, Morgenthaler NG, Squire IB, Davies JE, Bergmann A, Ng LL: C-terminal provasopressin (copeptin) as a novel and prognostic marker in acute myocardial infarction: Leicester Acute Myocardial Infarction Peptide (LAMP) study. Circulation 2007, 115:2103-2110.

36. Karakas M, Januzzi JL Jr, Meyer J, Lee H, Schlett CL, Truong QA, Rottbaue W, Bamberg F, Dasdemir S, Hoffmann U, Koenig W: Copeptin does not add diagnostic information to high-sensitivity troponin $\mathrm{T}$ in low- to intermediate-risk patients with acute chest pain: results from the rule out myocardial infarction by computed tomography (ROMICAT) study. Clin Chem 2011, 57:1137-1145.

37. Sabatine MS, Morrow DA, de Lemos JA, Omland T, Sloan S, Jarolim P, Solomon SD, Pfeffer MA, Braunwald E: Evaluation of multiple biomarkers of cardiovascular stress for risk prediction and guiding medical therapy in patients with stable coronary disease. Circulation 2012, 125:233-240.
38. Smith JG, Newton-Cheh C, Almgren P, Struck J, Morgenthaler NG, Bergmann A, Platonov PG, Hedblad B, Engstrom G, Wang TJ, Melander O: Assessment of conventional cardiovascular risk factors and multiple biomarkers for the prediction of incident heart failure and atrial fibrillation. J Am Coll Cardiol 2010, 56:1712-1719

39. Schnabel RB, Wild PS, Schulz A, Zeller T, Sinning CR, Wilde S, Kunde J, Lubos E, Lackner KJ, Warnholtz A, Gori T, Blankenberg S, Munzel T: Multiple endothelial biomarkers and noninvasive vascular function in the general population: the Gutenberg Health Study. Hypertension 2012, 60:288-295.

40. Rutschmann B, Evequoz D, Aubert JF, Brunner HR, Waeber B: Vasopressin dilates the rat carotid artery by stimulating V1 receptors. J CardiovasC Pharmacol 1998, 32:637-641.

41. Fluri F, Morgenthaler NG, Mueller B, Christ-Crain M, Katan M: Copeptin procalcitonin and routine inflammatory markers-predictors of infection after stroke. PLoS One 2012, 7:e48309.

42. Urwyler SA, Schuetz P, Fluri F, Morgenthaler NG, Zweifel C, Bergmann A, Bingisser R, Kappos L, Steck A, Engelter S, Muller B, Christ-Crain M, Katan M: Prognostic value of copeptin: one-year outcome in patients with acute stroke. Stroke 2010, 41:1564-1567.

43. Maturi MF, Martin SE, Markle D, Maxwell M, Burruss CR, Speir E, Greene R, Ro YM, Vitale D, Green MV, et al: Coronary vasoconstriction induced by vasopressin. Production of myocardial ischemia in dogs by constriction of nondiseased small vessels. Circulation 1991, 83:2111-2121.

44. Holmberg L, Nilsson IM, Borge L, Gunnarsson M, Sjorin E: Platelet aggregation induced by 1-desamino-8-D-arginine vasopressin (DDAVP) in Type IIB von Willebrand's disease. N Engl J Med 1983, 309:816-821.

45. Ye Z, Ali Z, Klee GG, Mosley TH Jr, Kullo IJ: Associations of candidate biomarkers of vascular disease with the ankle-brachial index and peripheral arterial disease. Am J Hypertens 2013, 26:495-502.

46. Li X, Yang XC, Sun QM, Chen XD, Li YC: Brain natriuretic peptide and copeptin levels are associated with cardiovascular disease in patients with chronic kidney disease. Chin Med J (Engl) 2013, 126:823-827.

47. Enhorning S, Bankir L, Bouby N, Struck J, Hedblad B, Persson M, Morgenthaler NG, Nilsson PM, Melander O: Copeptin, a marker of vasopressin, in abdominal obesity, diabetes and microalbuminuria: the prospective Malmo Diet and Cancer Study cardiovascular cohort. Int J Obes (Lond) 2013, 37:598-603.

48. Bhandari SS, Loke I, Davies JE, Squire IB, Struck J, Ng LL: Gender and renal function influence plasma levels of copeptin in healthy individuals. Clin Sci (Lond) 2009, 116:257-263.

49. Stachenfeld NS, Splenser AE, Calzone WL, Taylor MP, Keefe DL: Sex differences in osmotic regulation of AVP and renal sodium handling. J Appl Physiol 2001, 91:1893-1901.

50. Liu J, Sharma N, Zheng W, Ji H, Tam H, Wu X, Manigrasso MB, Sandberg K Verbalis JG: Sex differences in vasopressin V(2) receptor expression and vasopressin-induced antidiuresis. Am J Physiol Renal Physiol 2011, 300:F433-F440.

51. Garcia-Villalon AL, Sanz E, Monge L, Fernandez N, Martinez MA, Climent B, Dieguez G: Vascular reactivity to vasopressin during diabetes: gender and regional differences. Eur J Pharmacol 2003, 459:247-254.

52. Stallone JN: Role of endothelium in sexual dimorphism in vasopressininduced contraction of rat aorta. Am J Physiol 1993, 265:H2073-H2080.

53. Wang $Y X$, Crofton JT, Liu H, Sato K, Share L: V2-receptor blockade enhances pressor response to vasopressin: gender difference. Life SCi 1996, 59:695-703.

doi:10.1186/1475-2840-12-168

Cite this article as: Then et al:: Plasma copeptin levels are inversely associated with intima-media-thickness in men: the population-based KORA F4 study. Cardiovascular Diabetology 2013 12:168. 